\title{
Extensive Vulvar Hematoma as a Complication of Labiaplasty: A Case Report
}

\author{
Amal Al Mulla*, Humma Habib, Ousama Jarrad \\ OBSGYN \& Reproductive Medicine, Amina Hospital, Ajman, United Arab Emirates \\ Email: *amalalmulla2020@outlook.com
}

How to cite this paper: Al Mulla, A., Habib, H. and Jarrad, O. (2020) Extensive Vulvar Hematoma as a Complication of Labiaplasty: A Case Report. Open Journal of Obstetrics and Gynecology, 10, 880-885. https://doi.org/10.4236/ojog.2020.1070082

Received: June 8, 2020

Accepted: July 5, 2020

Published: July 8,2020

Copyright $\odot 2020$ by author(s) and Scientific Research Publishing Inc. This work is licensed under the Creative Commons Attribution International License (CC BY 4.0).

http://creativecommons.org/licenses/by/4.0/

\begin{abstract}
Vulvar hematoma is an extremely rare complication outside obstetric practice. Owing to the vulvar structure and its rich blood supply, hematoma can reach an enormous size over a short period. Although direct trauma is the anesthetic 31-year-old nullipara admitted for acute massive vulvar swelling as a complication of labiaplasty. She scored 10 on the pain scale. Upon admission to the emergency department, she had normal vital signs and was immediately started on intravenous acetaminophen and prophylactic antibiotics. The patient was subsequently transferred to the operating theater for examination and drainage of the hematoma under anesthesia. Reconstruction of the labia was performed. The patient had a smooth postoperative course and was discharged on the $3^{\text {rd }}$ postoperative day. We concluded that Anesthetic gynecological procedures, although categorized as minor, can result in grave sequelae, and must therefore be performed in a hospital set-up.
\end{abstract}

\section{Keywords}

Hematoma, Labiaplasty, Vulva, Anesthetic Gynecological Procedures

\section{Introduction}

The external female genitalia, known as the vulva, encloses the urethral opening and vaginal orifice. It has a rich blood supply and several nerve endings; therefore it is protected by a pad of fat, which gives the mons pubis and labia majora their convex contour [1].

Vulvar hematoma is the accumulation of blood in the subcutaneous tissues [2]. It is usually encountered in obstetric practice as a complication of vaginal birth with a reported incidence of 1:1000 [3]. Few cases of severe non-obstetric vulvar hematoma have been reported in the literature, with an overall incidence of 3.7\%, constituting less than $1 \%$ of all gynecological emergencies [4]. 
Vulvar hematomas can vary in size, from small to extensive. Small hematomas can be resolved with conservative management, while extensive hematomas require surgical drainage. Saddle injury, sexual assault, and direct trauma are frequent causes reported in the literature. Vulvar hematomas can result in enormous pain, disability, in addition to the psychological trauma. In extreme conditions, hypovolemic and/or neurologic shock can occur.

Here, we describe a rare case of a vulvar hematoma after labiaplasty.

\section{Case Presentation}

A 31-years-old nullipara underwent labiaplasty in a medical center to reduce the size of her labia minora for cosmetic reasons. The operating doctor noticed a rapidly increasing hematoma in the right labia majora that reached a large size in the span of 2 hours. The patient was in severe agony with intense genital pain and was transferred to our facility by ambulance. Upon arrival to the emergency department, initial examination revealed a hemodynamically stable condition with normal vital signs. Blood was collected for hemoglobin and coagulation profile, and cross matched blood was prepared. The patient was administered intravenous acetaminophen and first generation cephalosporins.

Initial vulvar examination revealed a large tense lump measuring approximately $10 \times 12 \mathrm{~cm}$ on the entire right vulvar area involving the labia majora, suggesting the presence of subcutaneous blood accumulation. The adjoining symphysis pubis and mons were edematous, swollen, and ecchymosed. Bilateral labia minora were absent. Sutures were visible on the areas of resection of the labia minora. Vaginal examination was not possible owing to obstruction of the vaginal orifice by the hematoma. We were also unable to identify the urethral opening at this point (Figure 1).

The patient was informed of the possible diagnosis and the need for surgical intervention. Written informed consent was obtained. Examination under spinal anesthesia was carried out using an aseptic technique with the patient in dorsal lithotomy. The vulvar anatomy was completely distorted due to the massive swelling, and a urinary catheter could not be inserted. The patient was then draped and positioned. The previous surgical sutures were opened along the lines of maximum tension. Multiple clots were removed, and the active bleeder identified on the lateral flap of the excised labia minora was ligated. The extent of the hematoma created extensive dead space between the muscle layers. This was irrigated with normal saline and obliterated by sutures. The operative site was then checked for active bleeding. The labia minora remnants were then reconstructed and complete hemostasis was achieved. A urinary catheter was inserted after drainage of the hematoma (Figure 2).

The patient had a smooth postoperative course and no difficulty in passing urine after removal of the urinary catheter. Swelling significantly reduced with minimal residual edema. The pain was minimal and easily controlled by mild analgesics. The patient was ambulatory after 6 hours. 


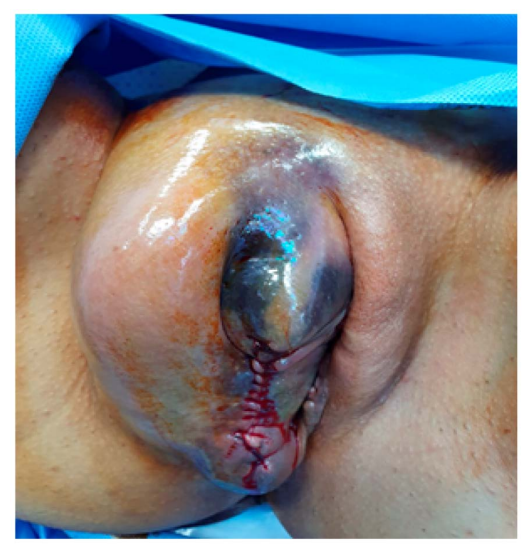

Figure 1. Preoperative examination reveals diffuse vulvar swelling with bluish discoloration.

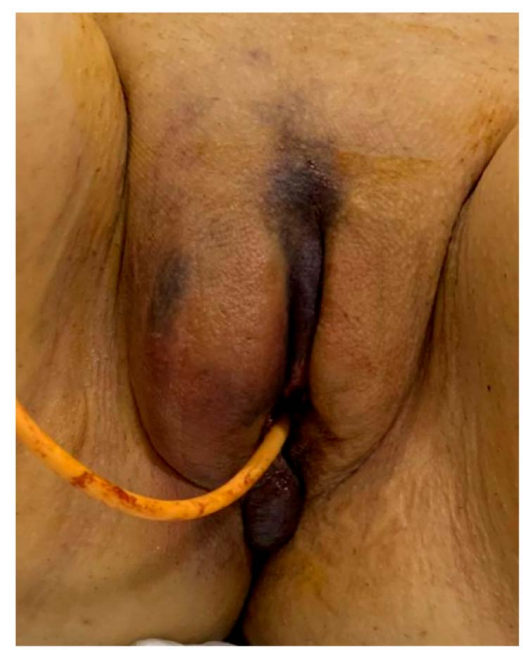

Figure 2. Immediate reduction in the swelling.

The patient was discharged in a good condition. Metronidazole and Doxycycline together with Ibuprofen were prescribed for a total of 10 days. Follow-up in the clinic after 2 weeks showed satisfactory healing (Figure 3 ).

\section{Discussion}

Anesthetic gynecological procedures include any surgical or non-surgical procedure intended to alter the vulvovaginal anatomy for cosmetic reasons in the absence of structural or functional indications [5]. Unfortunately, there are no high-quality data addressing the associated benefits, risks, and possible complications of these procedures, as per the American College of Obstetrician and Gynecologist Committee Opinion number 795 [5]. Labiaplasty is the most frequently performed procedure in this field. Although many techniques have been described, hematoma has not been reported as a complication [5]. The majority of reported Non-Obstetric hematomas resulted from direct vulvar injuries or from post-coital injury. To the best of our knowledge, this is the first reported case of vulvar hematoma as a complication of labiaplasty. 


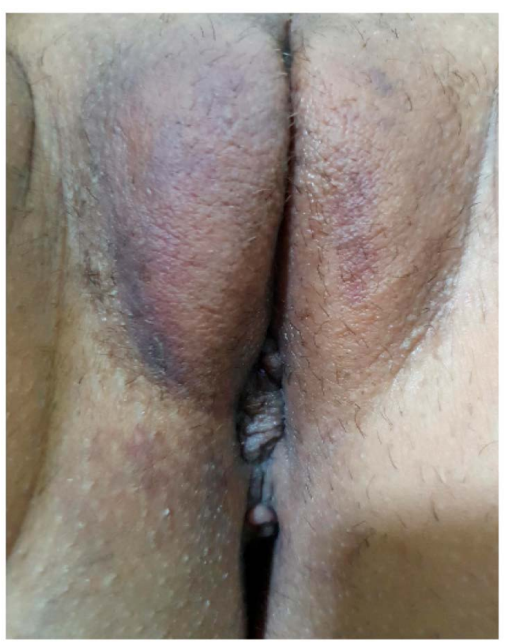

Figure 3. Day 12 postoperative review.

In total, $70 \%$ of vulvar hematomas are noted to be on the right side, although the exact etiology remains unknown [6]. The accumulated blood usually follows the cleavage planes and could easily dissect the areolar tissue, which offers little resistance. Hence, the hematoma can spread and reach an enormous size over a short duration.

Labiaplasty is a procedure that is gaining popularity nowadays and involves a reduction in the size of the labia minora [7]. It is performed primarily for cosmetic purposes, as many females prefer their labia minora to have a prepubertal appearance, i.e. contained and covered by their labia majora [8]. Gowda et al. explored the reasons for labiaplasty in 131 women and found that two thirds of them wanted to have the procedure for cosmetic purposes [7]. Moreover, hypertrophied labia could be troublesome for some females, with some experiencing repeated urinary tract infections due to poor hygiene, and a few even reporting superficial dyspareunia [9].

Labiaplasty techniques are variable and depend on the portion of the labia to be removed. The direct excision technique removes the whole labia minora, which is similar to the technique employed in our case [10]. Another approach is the wedge resection technique, which involves minimal tissue removal and preservation of the natural contour [11].

Injury to the labial branches can result in significant vulvar hematomas. Hence, conservative management is inappropriate, especially for acute rapidly expanding hematomas, as these can cause pressure necrosis in the surrounding structures [12]. Mangwi et al. described a post-coital hematoma in a 24-year-old P1 woman measuring $6 \times 7 \mathrm{~cm}$, which required surgical evacuation after failure of conservative measures [1].

Lapresa et al. described a similar case in a-44-year old women who sustained a massive vulvar hematoma following a fall from stairs [13].

In our patient, labiaplasty was carried out in a medical center for cosmetic purposes, with the aim of decreasing the length of the labia minora. We are unaware of the exact set-up and the surgical techniques used by the operator. 


\section{Conclusions}

Labiaplasty is the most common Anesthetic gynecological procedure. Patients must be individually assessed, and the exact indications for the use of this procedure must be explored. Risks and benefits should be discussed in detail. Psychological counselling may be beneficial in some cases. Surgical drainage is the treatment of choice in acute rapidly expanding hematomas.

We strongly recommend that these kinds of procedures be performed in a hospital setting by an adequately trained gynecologist.

\section{Ethical Considerations}

All procedures performed in studies involving human participants were in accordance with the ethical standards of the institutional and/or national research committee and with the 1964 Helsinki declaration and its later amendments or comparable ethical standards.

\section{Consent}

Informed consent was obtained for publication of the report and associated images.

\section{Conflicts of Interest}

The authors declare no conflicts of interest regarding the publication of this paper.

\section{References}

[1] Mangwi, A.A., Ebasone, P.V., Aroke, D., Ngek, L.T. and Nji, A.S. (2019) Non-Obstetric Vulva Haematomas in a Low Resource Setting: Two Case Reports. The Pan African Medical Journal, 33, 314. https://doi.org/10.11604/pamj.2019.33.314.19488

[2] Alcalde, M.V.L., Hernandez, E.H., Alfonso, S.B. and Sanchez, M.J.D. (2019) Non-Obstetric Traumatic Vulvar Hematoma: Conservative or Surgical Approach? A Case Report. Case Reports in Women's Health, 22, e00109. https://doi.org/10.1016/j.crwh.2019.e00109

[3] Awoleke, J.O. and Ipinnimo, O.M. (2017) Vulvovaginal Infralevator Haematoma Mimicking the Second Stage of Labour. Case Reports in Obstetrics and Gynecology, 2017, Article ID: 8062793. https://doi.org/10.1155/2017/8062793

[4] Papoutsis, D. and Haefner, H.K. (2017) Large Vulvar Haematoma of Traumatic Origin. Journal of Clinical and Diagnostic Research, 11, QJ01-QJ02. https://doi.org/10.7860/JCDR/2017/30104.10542

[5] Schnatz, P.F. and Boardman, L.A. (2020) Elective Female Genital Cosmetic Surgery. The American College of Obstetricians and Gynecologists Committee Opinion No. 795. Obstetrics \& Gynecology, 135, e36-e42. https://doi.org/10.1097/AOG.0000000000003616

[6] Schmidt, A.B. and Lykkebo, A.W. (2015) Post-Coital Genital Injury in Healthy Women: A Review. Clinical Anatomy, 28, 331-338. https://doi.org/10.1002/ca.22476

[7] Gowda, A.U., Chopra, N. and Khalifeh, M. (2015) Indications, Techniques and Complications of Labiaplasty. Eplasty, 15, ic46. 
[8] Motakef, S., Rodriguez-Feliz, J. and Chung, M.T. (2015) Vaginal Labiaplasty: Current Practices and a Simplified Classification System for Labial Protrusion. Plastic and Reconstructive Surgery, 135, 774-788. https://doi.org/10.1097/PRS.0000000000001000

[9] Wu, J.A., Braschi, E.J., Gulminelli, P.L. and Comiter, C.V. (2013) Labioplasty for Hypertrophic Labia Minora Contributing to Recurrent Urinary Tract Infections. Female Pelvic Medicine \& Reconstructive Surgery, 19, 121-123. https://doi.org/10.1097/SPV.0b013e31827de473

[10] Ellsworth, W.A., Rizvi, M. and Lypka, M. (2010) Techniques for Labia Minora Reduction: An Algorithmic Approach. Anesthetic Plastic Surgery, 34, 105-110. https://doi.org/10.1007/s00266-009-9454-5

[11] Furnas, H.J. (2017) Trim Labiaplasty. Plastic and Reconstructive Surgery-Glob Open, 5, e1349. https://doi.org/10.1097/GOX.0000000000001349

[12] Hernández-Tiria, M., Navarro-Devia, A. and Osorio-Ruiz, A. (2015) Lesión vulvar y perineal secundaria a trauma pelviperineal complejo: Presentación de un caso y revisión de la literatura. Revista Colombiana de Obstetricia y Ginecologia, 66, 297-305. https://doi.org/10.18597/rcog.295

[13] Alcalde, L., Victoria, M., et al. (2019) Non-Obstetric Traumatic Vulvar Hematoma: Conservative or Surgical Approach? A Case Reports. Case Reports in Women's Health, 22, e00109. https://doi.org/10.1016/j.crwh.2019.e00109 